\title{
Factors Influencing the Choice of an Agriculture Specialisation by Primary teachers' Diploma College Students in Swaziland
}

\author{
Alfred F. Tsikati \\ Lecturer: William Pitcher Teacher Training College \\ Barnabas M. Dlamini \\ Professor: Department of Agricultural Education and Extension, University of Swaziland \\ Micah B. Masuku (Corresponding author) \\ Associate Professor: Department of Agricultural Economics and Management, University of \\ Swaziland. E-mail: mbmasuku@uniswa.sz
}

Received: August 13, 2015 Accepted: August 28, 2015 Published: September 19, 2015.

doi:10.5296/jas.v4i1.8153 URL: http://dx.doi.org/10.5296/jas.v4i1.8153

\begin{abstract}
The choice of a specialisation is one of the lifetime career decisions students have to make when entering college. The purpose of the study was to determine factors that influence the choice of Agriculture specialisation by college student teachers in Swaziland. A desk review and a Modified Delphi technique were used to generate items used in the survey questionnaire for data collection. A census of 351 student teachers from three teacher training colleges was used. Data were analyzed by means of descriptive statistics and multinomial logistic regression. The findings of the study revealed that students' interest, department's image, sex and influence by professionals were the predictors for the choice of Agriculture specialisation in the teacher training colleges in Swaziland. The study recommends that the Agriculture departments in the colleges must stage campaigns and craft policies to promote the choice of the Agriculture specialisation. A study should be conducted to determine the influence of the subject combinations that make an area of specialisation on the choice of the Agriculture specialisation.
\end{abstract}

Keywords: Agriculture, multinomial regression, logistic regression, specialisation, teacher training colleges. 


\section{Introduction}

\subsection{Background}

Career choice including that of choosing a college major is one of the most important decisions to be made by a college student (Begs, Bentham \& Tyler, 2008). In some institutions information is provided to advise students in making correct decisions about the choice of a specialisation (Begs, Bentham \& Tyler, 2008; Schuster \& Costantino, 1986). The 2002 Guidelines and Regulations for Colleges Affiliated to the University of Swaziland indicate that there are three teacher training institutions offering Primary Teachers' Diploma (PTD) in Swaziland, these are Ngwane Teacher Training College, William Pitcher Teacher Training College and Nazarene Teacher Training College (now known as Southern Africa Nazarene University). The Guidelines and Regulations for colleges affiliated to the University of Swaziland provide information that guides students on the entrance requirements to each of the specialisation for the Primary Teachers Diploma.

The PTD is a three-year program offered to prospective primary school teachers. In the first two years of study, the student teachers are trained in all subjects taught at the primary schools in Swaziland and then choose a specialisation in third year. A specialisation is an option with a group of subjects, which the student teachers take in the teacher training colleges.

The PTD programme comprises of three groups of subjects (A, B, \& C). Group A is teaching practice which is the main professional component. It is of six weeks duration in second and third year respectively. Group B comprises core subjects taught at primary school level, which include English, Mathematics, siSwati, Science, Health, Agriculture, Home Economics, Education and Social Studies. Group C subjects include Arts and Craft, Physical Education, Numerical Skills and Academic Communication Skills (Passaic, Ben bow \& Simiane, 1990).

The choice of a college major or specialisation is one of the most important decisions a student has to make (Begs, Bentham \& Tyler, 2008). This decision has lifetime implications as students tend to have academic challenges if they happen to choose a subject specialisation in which they have no interest.

In Swaziland, several studies on specialisations and factors affecting the choice of a specialisation have been conducted at high school and university levels (Dlamini, 1993; Dube \& Habedi, 1989; Xaba, 2003) and none at the college level. Hence, factors influencing the choice of specialisation at teacher training college are not known. Findings of this study will guide PTD students in choosing Agriculture specialisation at the college level.

\subsection{Purpose and objectives of the study}

The purpose of the study was to determine factors influencing the choice of Agriculture specialisation by Primary Teachers Diploma student teachers in Swaziland. The specific objectives of the study were to:

i) Describe student teachers enrolled in a Primary Teachers' Diploma by college subject specialisation. 
ii) Describe student teachers enrolled in a Primary Teacher Diploma by their background and demographic characteristics.

iii) Compare the respondents' choices of subject specialisation by selected background and demographic variables.

iv) Predictor variables influencing student teachers enrolled in a Primary Teacher Diploma to choose Agriculture specialisation.

\subsection{Hypotheses of the study}

\subsubsection{Research hypothesis}

Student's interest is not a distinguishing factor in choosing Agriculture specialisation by the Primary Teacher Diploma student teachers in Swaziland.

\subsubsection{Alternative (plausible or rival) hypothesis}

The choice of Agriculture specialisation by student teachers enrolled in Primary Teachers' Diploma in Swaziland is not based on: student grade, outside college experience; college experience, department's image, professionals, subject combination, significant others, attitude and impressions; and background and demographic characteristics.

\section{Literature Review}

Exposure to a subject specialisation such as agriculture draws student teachers towards that particular specialisation (Wildman \& Torres, 2001). Interaction with professionals such as head teachers, teachers, lecturers, counsellors and school auxiliary staff positively influences the choice of a profession by student teachers. Similarly, families and friends of students also influence the choice of a subject specialisation (Wildman \& Torres, 2001).

Student interest was identified as one of the main factors influencing the choice of a specialisation (Dube \& Habedi, 1989; Esters, 2007; Mokalake, 2005; Samela, 2010; Wildman \&Torres, 2001). However, Jackman and Smith-Attisan (1992) argue that, family members only influence students to enrol in college without guiding them on the choice of a subject specialisation.

The course content, pedagogical strategies, reputation, friendliness of the department affect subject specialisation (Donnermeyer \& Kreps, 1994; Sutphin \& Newsom-Stewart, 1995). Consequently, the experience gained by student teachers at the college plays a critical role in the student's choice of agriculture (Jones \& Larke, 2001).

Beliefs and attitudes are good predictors for participation in an agricultural programme (Sutphin \& Newsom-Stewart, 1995). Beliefs and attitudes were reported to have an influence on the success of the Pre-vocational programme in Swaziland (Mndebele \& Dlamini, 1999).

Certain subject specialisations are associated with sex, as some are dominated by males, while others are dominated by females (Begs, Bentham \& Tyler, 2008; Samela, 2010). Student's locations are also considered important factors when choosing a subject specialisation (Whiteley \& Porter, 2000). 


\section{MlMacrothink}

\section{Conceptual Framework}

Figure 1 shows the conceptual framework of the study. The dependent variable in this study was PTD student teachers' subject specialisation. The dependent variable had four categories: Agriculture, Languages, Pure Sciences and Social Sciences. Respondents were asked to circle their subject specialisation. The major independent variable was student interest in choosing any area of specialisation. Students' specialisation choices are influenced by student interests (Dube \& Habedi, 1989; Edwards \& Quinter, 2011; Sutphin \& Newsom-Stewart, 1995). Interest was measured by requesting respondents to indicate their level of interest in choosing an area of specialisation. The scale used to rate each item was: $1=$ No interest, $2=$ Very low interest, $3=$ Low interest, $4=$ Moderate interest, $5=$ High interest, $6=$ Very high interest. The rival independent variables were student grade; outside-college exposure related to the specialisation; professionals, significant others; image of the department, experience in the college, and the influence of background and demographic characteristics.

Exposure to the related subject refers to prior student exposure related to a subject specialisation. Student grade relates to a grade used to admit student to the teacher training institution having an influence on the choice of a specialisation (Edwards \& Quinter, 2011; Whiteley \& Porter, 2000). Professionals are teachers, counsellors influencing students' choice of specialisation (Jackman \& Smith-Attisano, 1992). Significant others are other individuals such as relatives and friends influencing students' choice of programme or a specialisation (Wildman \& Torres, 2001). Department's image is how the students perceive

the department offering the subject specialisation (Donnermeyer \& Kreps, 1994). Subject combination means the combination of courses making up the specialisation. College experience is the experience gained by students at the college before choosing a specialisation. Beliefs and attitudes are attitudes or values held by students prior to their choice of specialisation. Demographic characteristics such as sex and student location are important factors when choosing a subject specialisation (Begs, Bentham \& Tyler, 2008; Samela, 2010; Whiteley \& Porter, 2000).

The rival independent variables were measured by requesting respondents to rate each item on a scale: 1 = No influence, $2=$ Low influence, $3=$ Slightly low influence, $4=$ Slightly High influence, 5 = High influence, $6=$ Very high influence. Background and demographic characteristics were obtained by requesting respondents to tick or fill in the requested information. 


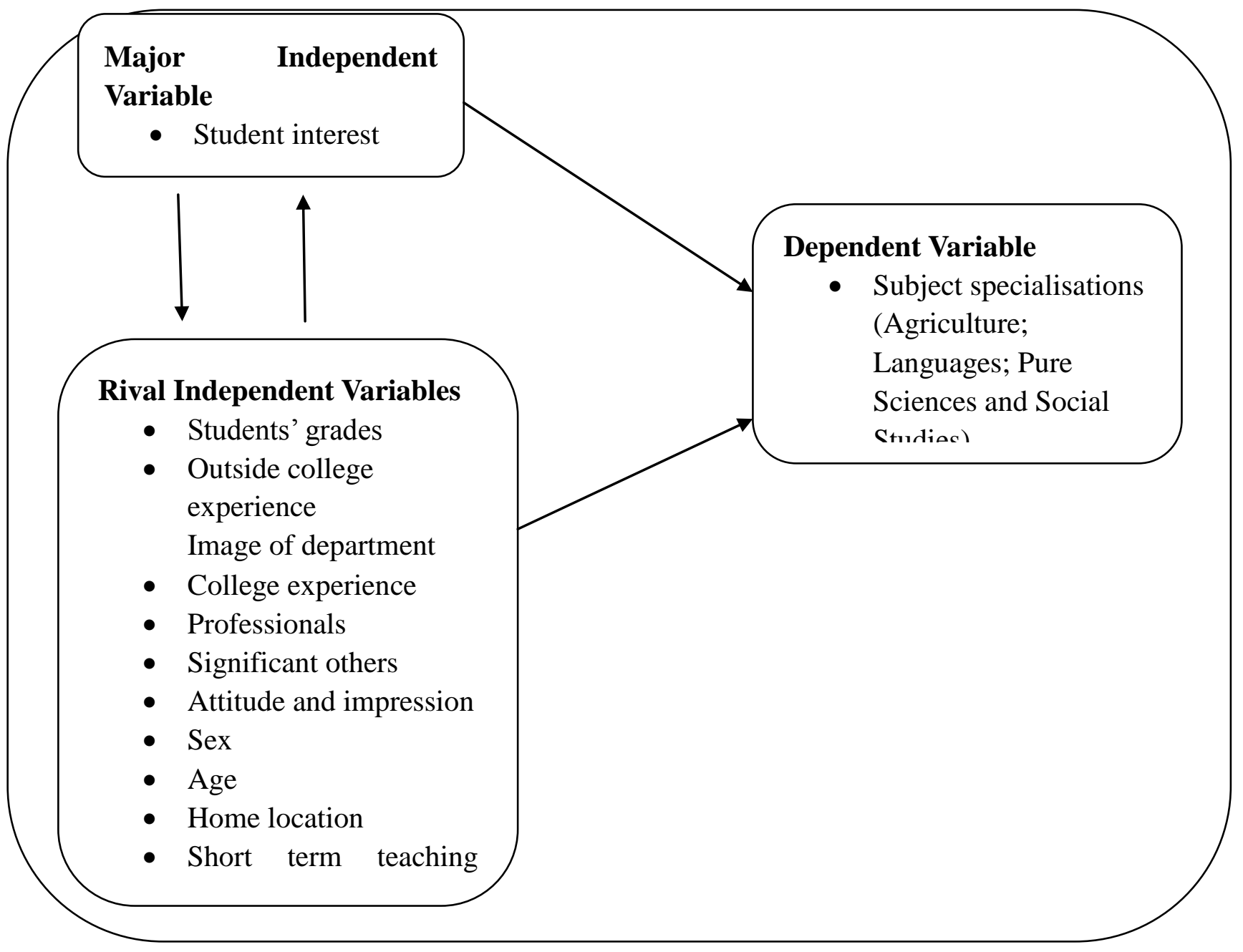

\section{Methodology}

The study was a descriptive predictive research employing multinomial logistic regression procedures. Multinomial logistic regression is used when the dependent variable is a nominal with more than two categories. A triangulation of desk review, modified Delphi technique and a survey questionnaire were used for data collection. The outcomes from the desk review and modified Delphi technique were used to develop the survey questionnaire. The questionnaire was used for data collection to determine factors predicting the choice of Agriculture by PTD student teachers.

The target population was a census of the 2012/2013 third year PTD students $(\mathrm{N}=351$ ) from Ngwane Teacher Training College; Nazarene Teacher Training College and William Pitcher Teacher Training College. The instrument was validated through the Delphi process. Reliability coefficients ranged between 0.61 and 0.90 for the domains.

Data were collected in May 2013 using self-administered questionnaires. There were nine non-respondents and non-response error was controlled by comparing the means of early and late respondents (Miller \& Smith, 1983). There was no significant difference between the early and late respondents $(\mathrm{t}=0.63, \mathrm{p}=0.54)$. Thus, the findings were generalizable to the 
target population. Using SPSS Version 20 data were analysed through descriptive statistics, and multinomial logistic regression. An a priori probability level of .05 was established to determine the level of statistical significance of factors that influenced the choice of agriculture specialisation. The multinomial regression model used was:

$$
\operatorname{In}[\mathrm{p} /(1-\mathrm{p})]=\alpha+\beta_{1} \mathrm{X}_{1}+\beta_{2} \mathrm{X}_{2}+\ldots \beta_{\mathrm{k}} \mathrm{X}_{\mathrm{k}}
$$

Where: $\ln [\mathrm{p} /(1-\mathrm{p})]=$ is the $\log$ odds ratio, or "logit"

$$
\begin{gathered}
\mathrm{P} /(1-\mathrm{p})=\text { is the "odds ratio" } \\
p=\text { probability that the event } Y \text { occurs, } \mathrm{p}(\mathrm{Y}=1) \\
\alpha=\text { the } Y \text { intercept } \\
\beta=\text { the regression coefficient, } \\
\mathrm{X}_{1 . \mathrm{k}}=\text { variables of the study }
\end{gathered}
$$

\section{Results and Discussion}

The results are discussed in terms of the following: college subject specialisation: level of interest in a specialisation, rival independent variables, background and demographic characteristics of respondents, comparing the respondents' choices of subject specialisation, and predictors for choosing Agriculture specialisation.

\begin{tabular}{|c|c|c|c|c|c|c|c|c|}
\hline \multirow{2}{*}{ Specialisation } & \multicolumn{2}{|c|}{$\begin{array}{l}\text { NTTC } \\
\text { N=149 }\end{array}$} & \multicolumn{2}{|c|}{$\begin{array}{l}\text { SANU } \\
\mathbf{N}=135\end{array}$} & \multicolumn{2}{|c|}{$\begin{array}{l}\text { WPC } \\
\text { N=58 }\end{array}$} & \multicolumn{2}{|c|}{$\begin{array}{c}\text { Total } \\
\mathrm{N}=342\end{array}$} \\
\hline & $\mathbf{f}$ & $\%$ & $\mathbf{f}$ & $\%$ & f & $\%$ & f & $\%$ \\
\hline Agriculture & 39 & 11.4 & 25 & 7.3 & 20 & 5.8 & 84 & 24.6 \\
\hline Languages & 36 & 10.5 & 32 & 9.4 & 8 & 2.3 & 76 & 22.2 \\
\hline Pure Sciences & 32 & 9.4 & 33 & 9.6 & 16 & 4.7 & 81 & 23.7 \\
\hline \multirow[t]{2}{*}{ Social Studies } & 42 & 12.3 & 45 & 13.2 & 14 & 4.1 & 101 & 29.5 \\
\hline & 149 & 43.6 & 135 & 39.5 & 58 & 16.9 & 342 & 100.0 \\
\hline
\end{tabular}

\subsection{Objective one - Distribution of respondents by subject specialisation}

Table 1 indicates that a majority (29.6\%) of the respondents specialized in Social Studies; followed by respondents who specialized in Agriculture $(24.6 \%)$ and then Pure Science (23.7\%). Languages had the least number of student teachers $(22.2 \%)$.

Table 1. Distribution of student teachers by college subject specialisation

Note. DV = Area of specialisation: $1=$ Agriculture, $2=$ Languages, $3=$ Pure Sciences, $4=$ Social studies.

\subsection{Objective two - Description of respondents by background and demographic characteristics}

Table 2 presents the demographic variables of the respondents. About two thirds (219 or $64.0 \%$ ) of the respondents were females. This finding is consistent with previous findings 
that females dominate jobs in social sciences (Lackland, 2001). A majority of the respondents were in the aged between 20-25 years $(n=166,48.5 \%)$. About $85 \%$ of the respondents were living in rural areas. A few of the respondents (17.5\%) had prior short-term teaching contract before enrolling for the PTD programme. A majority (66.7\%) of the student teachers were influenced by the subject combination in choosing a subject specialisation at the college.

Table 2. Description of respondents' background and demographic characteristics by specialisation

\begin{tabular}{|c|c|c|c|c|c|c|c|c|c|c|}
\hline \multirow[t]{2}{*}{ Variable } & \multicolumn{2}{|c|}{$\begin{array}{l}\text { Agriculture } \\
(\mathrm{N}=84)\end{array}$} & \multicolumn{2}{|l|}{$\begin{array}{l}\text { Languages } \\
(\mathrm{N}=76)\end{array}$} & \multicolumn{2}{|c|}{$\begin{array}{l}\text { Pure Science } \\
(\mathrm{N}=81)\end{array}$} & \multicolumn{2}{|c|}{$\begin{array}{l}\text { Social Studies } \\
(\mathrm{N}=101)\end{array}$} & \multicolumn{2}{|c|}{$\begin{array}{l}\text { Overall } \\
(\mathrm{N}=342)\end{array}$} \\
\hline & $\mathrm{f}$ & $\%$ & $\mathrm{f}$ & $\%$ & $\mathrm{f}$ & $\%$ & $\mathrm{f}$ & $\%$ & $\mathrm{f}$ & $\%$ \\
\hline \multicolumn{11}{|l|}{ Sex } \\
\hline Female & 70 & 83.3 & 54 & 71.1 & 37 & 45.7 & 58 & 57.4 & 219 & 64.0 \\
\hline Male & 14 & 16.7 & 22 & 28.9 & 44 & 54.3 & 43 & 42.6 & 123 & 36.0 \\
\hline \multicolumn{11}{|l|}{ Age } \\
\hline $20-25$ & 46 & 54.8 & 43 & 56.6 & 38 & 46.9 & 39 & 38.6 & 166 & 48.5 \\
\hline $26-30$ & 29 & 34.5 & 26 & 34.2 & 34 & 42.0 & 39 & 38.6 & 128 & 37.4 \\
\hline $31-35$ & 9 & 10.5 & 6 & 7.9 & 8 & 9.9 & 20 & 19.8 & 43 & 12.6 \\
\hline $36-40$ & 0 & 0 & 1 & 1.3 & 1 & 1.2 & 3 & 3.0 & 5 & 1.5 \\
\hline \multicolumn{11}{|c|}{ Home location } \\
\hline Urban & 16 & 19.0 & 19 & 25.0 & 15 & 18.5 & 17 & 16.8 & 67 & 19.6 \\
\hline Rural & 68 & 81.0 & 57 & 75.0 & 66 & 81.5 & 84 & 83.2 & 275 & 80.4 \\
\hline \multicolumn{11}{|c|}{ Short term teaching contract } \\
\hline No & 76 & 90.5 & 58 & 76.3 & 66 & 81.5 & 82 & 81.2 & 282 & 82.5 \\
\hline Yes & 8 & 9.5 & 18 & 23.7 & 15 & 18.5 & 19 & 18.8 & 60 & 17.5 \\
\hline \multicolumn{11}{|c|}{ Influenced by subject combination } \\
\hline No & 27 & 32.1 & 21 & 27.6 & 30 & 37.0 & 36 & 35.6 & 114 & 33.3 \\
\hline Yes & 57 & 67.9 & 55 & 72.4 & 51 & 63.0 & 65 & 64.4 & 228 & 66.7 \\
\hline
\end{tabular}

5.3 Objective three - Comparing the respondents' choices of subject specialisation by selected background and demographic variables

A Chi-square test was conducted to compare the frequencies between the dependent variable and selected demographic and background variables (Table 3). A statistically significant difference existed between college specialisation and sex (chi-square $=31.03, \mathrm{p}<.01$ ). Several studies revealed that the representation of women in scientific majors was low (Lackland, 2001).

Table 3. Comparison between the specialisation with demographic and background variables

\begin{tabular}{lcc}
\hline Variables & $\boldsymbol{X}^{2}$ & $\boldsymbol{p}$ \\
Sex & 31.03 & $.00^{*}$ \\
Age & 13.72 & .13 \\
Home location & 2.08 & .55 \\
Subject combination & 1.75 & .63 \\
Short-term teaching contract & 5.70 & .13 \\
\hline
\end{tabular}

$*=\mathrm{p} \leq .001$

5.4 Objective four - Explanatory and predictor variables for the choice of a specialisation

A multinomial logistic regression analysis was conducted to predict the choice of subject 
specialisation by 342 student teachers from three colleges in Swaziland (Table 4). Findings revealed that predictors of a choice of subject specialisation by college students were image of the college department, student interest in the specialisation and teaching experience (short term teaching contract). In order for the multinomial logistic regression model to be true or acceptable to explain and predict a dependent variable, the following conditions must be satisfied to assess the success of the model: 1) the overall relationship must be statistically significant - using the Test full model; 2) there must be no evidence of multi-collinearity; 3) and the stated individual relationship must be statistically significant and interpreted correctly (Agresti, 1996; Agresti \& Finlay, 1997).

A logistic model is said to provide a better fit to the data if it demonstrates an improvement over the intercept only model (null model). The test of the full model against the constant only model was statistically significant (Chi square $=126.937, \mathrm{p}<.01$ ). The Hosmer-Lemeshow (H-L) goodness-of-fit test also confirmed that the model was significant (Chi-square $=9843.816, p>.05)$. The Nagelkerke's $\mathrm{R}^{2}$ was 0.34 . This value indicates that the fitted model could account for $34 \%$ of the variance.

There was no evidence of multicollinearity problems in the solution of the choice of subject specialisation as the standard errors for the ' $b$ coefficients' were all less than 2.0. The model of fit indicated that the model was acceptable.

The Likelihood ratio test statistics (Model Chi-Square) determines if there is a statistical relationship between the dependent variable and the combination of the independent variables. The Likelihood ratio tests for this study demonstrated that generally, significant factors for a choice of Agriculture at the college were interest (Chi-square $=21.163, \mathrm{p}<.01$ ), department image (Chi-square $=18.839, \mathrm{p}<.01)$, professionals (Chi-square $=8.944, \mathrm{p}<.05$ ), and sex (Chi-square $=28.319, \mathrm{p}<.01)$. Interpretation is done only for independent variables that significantly distinguish between pairs of groups and having an overall relationship with the dependent variable in the likelihood ratio test.

Table 4. Parameter estimate for individual variable contribution

\begin{tabular}{lrrrrrrrrr}
\hline & \multicolumn{3}{c}{ Languages } & \multicolumn{3}{c}{ Pure Sciences } & \multicolumn{3}{c}{ Social Studies } \\
& $\mathbf{B}$ & Wald & $\mathbf{E x p}(\mathbf{B})$ & $\mathbf{B}$ & Wald & $\mathbf{E x p}(\mathbf{B})$ & $\mathbf{B}$ & Wald & $\operatorname{Exp}(\mathbf{B})$ \\
\hline $\mathbf{X}_{\mathbf{0}}$ & 3.23 & 2.31 & - & 1.96 & .79 & - & 1.73 & .72 & - \\
$\mathbf{X}_{\mathbf{1}}$ & -.03 & $12.44^{*}$ & .41 & -.56 & $4.39^{*}$ & .57 & -.97 & $15.33^{*}$ & .38 \\
$\mathbf{X}_{\mathbf{2}}$ & .30 & 2.28 & 1.36 & .27 & 1.91 & 1.32 & .09 & .22 & 1.10 \\
$\mathbf{X}_{\mathbf{3}}$ & -.04 & .05 & .95 & -.12 & .38 & .88 & -.04 & .05 & .95 \\
$\mathbf{X}_{\mathbf{4}}$ & .45 & $3.18^{*}$ & 1.57 & .41 & 2.70 & 1.51 & .51 & 4.38 & 1.67 \\
$\mathbf{X}_{\mathbf{5}}$ & -.60 & $5.91^{*}$ & .54 & -.67 & $7.33^{*}$ & .51 & -.94 & $14.49^{*}$ & .39 \\
$\mathbf{X}_{\mathbf{6}}$ & .08 & .14 & 1.08 & .38 & $4.18^{*}$ & 1.48 & .54 & 8.34 & 1.72 \\
$\mathbf{X}_{\mathbf{7}}$ & -.12 & .45 & .88 & .08 & .20 & .92 & .11 & .41 & 1.12 \\
$\mathbf{X}_{\mathbf{8}}$ & .24 & 2.82 & 1.27 & -.11 & $.31^{*}$ & 4.55 & .28 & 3.94 & 1.32 \\
$\mathbf{X}_{\mathbf{9}}$ & -.72 & 3.03 & .44 & -1.84 & $21.70^{*}$ & .16 & -1.35 & $11.85^{*}$ & .26 \\
$\mathbf{X}_{\mathbf{1 0}}$ & .03 & .34 & 1.03 & .03 & .21 & 1.03 & .11 & $3.81^{*}$ & 1.11 \\
$\mathbf{X}_{\mathbf{1 1}}$ & .47 & 1.28 & 1.61 & .14 & .09 & 1.15 & -.03 & .04 & .98 \\
& & & & & & & & &
\end{tabular}




\begin{tabular}{rrrrrrrrrr}
$\mathbf{X}_{12}$ & -1.06 & $4.26^{*}$ & .35 & -.88 & 2.81 & .42 & -.72 & 2.01 & .49 \\
$\mathbf{X}_{13}$ & -.13 & .11 & .88 & .36 & .99 & 1.44 & .16 & .20 & 1.17 \\
\hline
\end{tabular}

Coding: Variables: $\mathrm{X}_{0}=$ Intercept; $\mathrm{X}_{1}=$ Student interest; $\mathrm{X}_{2}=$ College grades; $\mathrm{X}_{3}=$ Outside; college experience; $\mathrm{X}_{4}=$ College experience; $\mathrm{X}_{5}=$ Department image; $\mathrm{X}_{6}=$ Professionals; $\mathrm{X}_{7=}$ Significant others; $\mathrm{X}_{8}=$ Attitude and impression; $\mathrm{X}_{9}=\mathrm{Sex} ; \mathrm{X}_{10}=$ Age; $\mathrm{X}_{11}=$ Home location; $\mathrm{X}_{12}=$ Short-term teaching contract; $\mathrm{X}_{13}=$ Subject combination.

Reference category: an Agriculture specialisation, ${ }^{*} \mathrm{P} \leq .05$ (alpha level).

The Wald criterion indicates that the interest (Wald $=12.44, \mathrm{p}<.01$ ); image of department (Wald $=5.91, \mathrm{p}<.05)$; and short-term teaching contract (Wald $=4.26, \mathrm{p}<.05)$ were the only independent variables that were significant in distinguishing between the choice of Languages specialisation and Agriculture specialisation. Even though college experience (Wald = 3.18, $\mathrm{p}<.05$ ); and attitude and impressions (Wald $=4.82, \mathrm{p}<.05$ ) were also statistical significant, they were not considered because they were not statistically significant in the overall model.

The Exponential Beta (Exp (B)) was used to explain the effect of the independent variable on the "odds ratio". The Exponential Beta value indicates that student teachers with less interest were less likely to choose the Languages specialisation, rather than Agriculture specialisation at college. This finding that interest is the main factor in the choice of a specialisation is consistent with Wildman and Torres (2001) findings. The Exponential Beta value further shows that when the level of interest was raised by one unit the odds ratio decreased by .41. It implies that for every unit increase in interest there is a decrease of 59\% $(.41-1=0.59)$ in the probability of choosing languages specialisation.

Student teachers who had a low perception about the image of department were less likely to choose Languages specialisation, rather than Agriculture specialisation. Donnermeyer and Kreps (1994) found that the image of the department could either sway away or toward itself students when making decisions on subject specialisation. For each unit increase in the image of department, the odds ratio decreased by .54. This literally meant that a unit increase in the perceived level of influence by the department image decreased the probability of choosing Languages by $46 \%$.

The Exponential Beta value indicates that student teachers who had no prior exposure to teaching were less likely to choose Languages rather than Agriculture specialisation at the college. Sutphin and Newsom-Stewart (1995) postulated that experience in a related specialization drew students towards that particular subject area of specialisation. When short term teaching contract was raised by one unit the odds ratio decreased by 35 . In other words, an increase of one year in the number of years student teachers were exposed to teaching reduced the probability of choosing for Languages specialisation by $65 \%$.

The Wald criterion also demonstrated that interest (Wald $=4.39, \mathrm{p}<.05$ ); department image $($ Wald $=7.33, \mathrm{p}<.01)$; professionals $($ Wald $=4.18, \mathrm{p}<.05)$ and sex $($ Wald $=21.70, \mathrm{p}=.00)$ were statistically significant in differentiating between choosing Pure Sciences and an Agriculture specialisation. However, attitude and impressions (Wald $=.31, \mathrm{p}<.05$ ) were not 
considered because they were not statistically significant in the Likelihood ratio test.

The Exponential Beta value indicates that student teachers with less interest were less likely to choose a Pure Sciences specialisation, rather than Agriculture specialisation. Esters (2007) noted that interest in agriculture was one of the major factors influencing the decisions of students to enrol in the subject. The Exponential Beta value further shows that when interest was raised by one unit the odds ratio declined by 0.57 . It implied that for a unit increase in the level of interest the chances of choosing Pure Sciences at college decreased by $43 \%$.

The Exponential Beta value also indicated that student teachers who had low perception of the department image were less likely to choose a Pure Sciences specialisation, rather than Agriculture specialisation. Wildman and Torres (2001) concluded that if the department was friendly, students would select specialisation from that particular department. One unit increase in the perceived influence level of the department image resulted in the odds ratio for choosing Pure Sciences at the college decreasing by 0.51 . Thus, for each unit increase in the level of the department's image, the odds declined by $49 \%$.

The Exponential Beta value indicates that student teachers receiving advice from professionals were likely to choose a Pure Sciences specialisation, rather than Agriculture specialisation. A study by Jones and Larke (2001) revealed statistically significant differences between the choice of agriculture by students associated with individuals employed in agriculture related fields and those who were not associated with such individuals. However, Dlamini (1993) reported that individuals working for an institution did not influence student choice. The Exponential Beta value further shows that when the level of professional advice was raised by one unit the odds ratio multiplied by 1.48 . Thus, for a unit increase in the level of professional advice the chances of choosing Pure Sciences instead of Agriculture increased by $48 \%$.

The Exponential Beta value also indicated that female student teachers were less likely to choose Pure Sciences, rather than an Agriculture specialisation. Generally, female students shun hard sciences (Lackland, 2001). When the number of respondents increased by a female student teacher the odds ratio decreased by .16. It implied that when the respondents were raised by a female, the female student teachers were $84 \%$ less likely to choose Pure Sciences rather than Agriculture specialisation.

Finally, the Wald criterion demonstrated that interest (Wald $=15.33, \mathrm{p}<.01$ ), department image $($ Wald $=14.49, \mathrm{p}<.01)$; and, sex $($ Wald $=11.85, \mathrm{p}<.01)$ were statistically significant in differentiating between the choice of Social Studies specialisation than Agriculture specialisation. Even though respondents' age (Wald $=2.012, \mathrm{p}<.05$ ) was statistically significant, it was not considered because it was not statistically significant in the Likelihood ratio test.

The Exponential Beta values indicated that student teachers with less interest were less likely to choose Social Studies specialisation, rather than Agriculture specialisation. This is consistent with the findings of the study by Dube and Habedi (1989) that concluded that student interest is the main factor for the choice of a specialisation. The Exponential Beta 
value further revealed that when interest level was raised by one unit the odds ratio declined by .38. It implied that for each unit increase in the level of interest, the likelihood of choosing Social Studies decreased by $62 \%$.

The Exponential Beta value indicated that a student teacher who had a low perception of the department image was less likely to choose Social Studies specialisation, rather than Agriculture specialisation. Naylor and Sanford (1980) concluded that the strength of the department was the most frequent reason cited by students to enrol in department. One unit increase in the perceived influence level of department's image resulted in the odds of choosing Social Studies decreasing by .39. Thus, for a unit increase in the image of department, the likelihood declined by $61 \%$.

Lastly, Exponential Beta values indicated that male student teachers were less likely to choose Social Studies, rather than an Agriculture specialisation. Generally, more male students enrol for science related disciplines than their female counterparts (Lackland, 2001). When the number of respondents was raised by a female student teacher the odds ratio decreased by 0.26 . It implied that the probability of female student teachers choosing Social Studies was $74 \%$ less likely.

\section{Conclusion and Recommendations}

\subsection{Conclusion}

The conclusion drawn is that student teachers at teacher training colleges in Swaziland are more interested in Agriculture than the other specialisations. Interestingly, the colleges are producing more PTD teachers with Social Studies than the other subject specialisation because agriculture caters for a limited number of students. Another conclusion drawn was that interest and departmental image were the important predictors for choosing the Agriculture specialisation by college students compared with other specialisations. Beliefs and attitudes were also competing with student interest when students choose agriculture specialisation. Professionals were likely to advise students to choose other specialisation i.e. Pure Science than Agriculture. Student teachers with prior teaching practice exposure in Agriculture are more likely to major in agriculture at the college. Female student teachers are more likely to specialise in social sciences than to either applied or pure sciences. The male student teachers choose applied or pure science than social sciences. A majority of student teachers were from rural areas, hence their interest in the Agriculture. This could be attributed to their possible exposure to farm activities at their homes.

The research hypothesis was accepted because student interest was the main factor influencing the choice of agriculture specialisation, and the alternative hypotheses were rejected.

\subsection{Recommendations}

The study recommended that colleges must use students' interest as their benchmark when advising students on the choice of their specialisation. The agriculture department should maintain the good image as it has been found to attract more learners. It is also recommended 
that the Agriculture department markets itself by staging campaigns, and craft policies that would promote the subject and attract more student teachers.

Furthermore, it is also recommended that further research must be conducted to establish the effects of specializing in agriculture on the performance of student teachers in their first year of teaching. There is a need for a tracer study on the progression of the student teachers on completion of their diploma with their specialisation in agriculture.

\section{References}

Agresti, A. (1996). Categorical data analysis (2nd ed). New York: John Wiley and Sons Inc.

Agresti, A., \& Finlay, B. (1997). Statistical methods for the social sciences (3rd ed). New York. Upper Saddle River, NJ: Prentice Hall, Inc.

Begs, J. M., Bentham J. H., \& Tyler, S. (2008). Distinguishing the factors Influencing College Students' Choice of Major. College Student Journal, 4(22), 381-394. Retrieved from http://www.eric.ed.gov.

Dlamini, M. P. (1993). Predictors of college students' reasons for pursuing program of study and enrolling in tertiary institutions in Swaziland. UNISWA Journal of Agriculture, 2, 64-69.

Donnermeyer, J. F., \& Kreps, G. M. (1994). Assessing college of Agriculture freshmen. NACTA Journal, 38(1), 45-48.

Dube, M. A., \& Habedi, M. K. (1989). Factors influencing students to enrol in the Faculty of Agriculture at the University of Swaziland. Research Project.

Edwards, K., \& Quinter, M. (2011). Factors influencing students career choices among secondary school students in Kisumu Municipality, Kenya. Journal of Emerging Trends in Educational Research and Policy Studies, 2(2) 81-87.

Esters, L. T. (2007). Factors influencing post-secondary education enrolment behaviours of urban Agriculture students. Career and Technical Education Research, 32(2), 79-98.

Jackman, W. J., \& Smith-Attisan, O. R. A. (1992). Qualitative and quantitative methods add depth to recruiting study. NACTA Journal, 3(1), 46-50.

Jones, W. A., \& Larke, A. (2001).Factors influencing career choice of African American and Hispanic Graduates of a Land Grant Institution. Journal of Agriculture, 42(1), 38-48.

Lackland, A. C. (2001). Students' choices of college majors that are gender traditional and non-traditional. Journal of College Student Development, 42(1), 39-47

Miller, L. E., \& Smith, K. L. (September /October 1983). Handling nonresponse issues. Journal of Extension, 21(5), 45-50.

Mndebele, C. B. S., \& Dlamini, Z. C. (1999). Parent related problems associated with Home based vocational Agriculture projects: the case of Swaziland. Journal of International Agricultural and Extension Education, 6(1), 37-44. 


\section{Macrothink}

Journal of Agricultural Studies

ISSN 2166-0379

2016, Vol. 4, No. 1

Mokalake, V. P. (2005). Perceptions of Botswana Senior Secondary Schools student regarding the subject selection process in their schools. Unpublished Master's Thesis, University of Swaziland, Luyengo, Swaziland.

Multinomial logistic regression [Power Point slides]. (n.d.). Retrieved from http://www.utexas.edu

Naylor, P. D., \& Sanford, T. R. (1980). Educational maturity, race and the selection of a college. AIR Forum 1980 paper, University of North Carolina. Chapel Hill NC.

Passaic, D., Ben bow, J. B., \& Simelane, M. (1990). The final impact evaluation of the Swaziland teacher training project. Washington, D. C. Britain. Creative Associates International, Inc.

Samela, T. (2010). Who is joining physics and why? Factors influencing the choice of Physics among Ethiopian university students. International Journal of Environmental and Science education, 5(3), 319-340.Retrieved from http://www.ijese.com.

Schuster, C. P., \& Costantino P (1986). Using marketing research to develop student recruiting strategies. NACTA Journal, 30(10), 5-9.

Sutphin M., \& Newsom-Stewart, H. D. (1995). Student's rationale for selection of an Agricultural related course in the high school by gender. Journal of Agriculture, 36(2), 55-61.

University of Swaziland (2002). Guidelines and regulations for colleges affiliated to the University of Swaziland. Kwaluseni, Swaziland.

Wedeen, P. (2007). Student's Perception of Geography: Decision making at age 14. Education Matters, 92(1). Retrieved from http://www.geography.org.

Whitely, S., \& Porter, J. (2000). Student perceptions on subject selection, longitudinal perspectives from Queensland school. Retrieved from http://www.aare.edu.au/98262htm.

Wildman, M., \& Torres, R. (2001). Factors identified when selecting a major in Agriculture. Journal of Agriculture, 42(2), 46-56.

Xaba, S. K. (2003). Factors affecting academic selection of prevocational education subjects in Swaziland High Schools. Unpublished Master's Thesis, University of Swaziland, Luyengo, Swaziland.

\section{Copyright Disclaimer}

Copyright for this article is retained by the author(s), with first publication rights granted to the journal.

This is an open-access article distributed under the terms and conditions of the Creative Commons Attribution license (http://creativecommons.org/licenses/by/3.0/). 